\title{
Views on Conflict related to the Causes of Conflict and the Management Strategies
}

\author{
Armando Dermaku ${ }^{1}$, Eros Balliu ${ }^{1}$ \\ ${ }^{1}$ Faculty of Social Sciences, University of Tirana, Albania
}

\begin{abstract}
This article discusses the Views of Conflict related to the Factors Causing Conflict and Conflict Management Strategies. The results of the discussion show that other potential sources of conflict are personal factors which include the value system that each individual has, personality characteristics that cause individuals to be unique and different from other individuals. The fact shows that certain personality types, such as individuals who are very authoritarian, dogmatic, and have low regard for others, are potential sources of conflict. If one of these conditions occurs in a group, and employees are aware of it, then the perception arises that in the group there is a conflict. Each group has different goals and each strives to achieve them. This problem occurs because when groups become more attached to their own goals or norms. This situation is called perceived conflict. The problem solving strategy in conflict is the basic assumption that all parties have a desire to handle the conflict that occurs and therefore it is necessary to find measures that can satisfy the parties involved in the conflict. On the basis of these assumptions, the problem solving strategy must always go through two important stages, namely the process of finding ideas and the process of maturing them.
\end{abstract}

Keywords: Conflict, Conflict Management, Organization

Received: December 20, 2020

Revised: December 26, 2020

Accepted: January 2, 2021

\section{Introduction}

A leader who wants to advance his organization must understand the factors that cause conflict, both conflicts within individuals and conflicts between individuals and conflicts within groups and conflicts between groups. Understanding these factors will facilitate the task in terms of resolving conflicts that occur and channeling them towards positive developments.

According to Nemeth (2004) there are different views on the role of conflict in groups or organizations. There are those who argue that conflict should be avoided or eliminated, because if it is ignored it will harm the organization. Contrary to this, another opinion states that if the conflict is managed in such a way, it will bring benefits to groups and organizations. Stoner and Freeman call this conflict an organizational conflict.

\section{Literature Review}

This contradiction of opinion by Robbins et.al (1996) is referred to as the Conflict Paradox, namely the view that on the one hand conflict is considered to improve group performance, but on the other hand most groups and organizations try to minimize conflict. In the description below, several views on conflict are presented, as stated by Robbins (1996).

\section{The Traditional View}

Defined by Balasubramanian \& Bhardwaj (2004) stated that all conflict is bad. Conflict is seen as something negative, harmful and should be avoided. To strengthen this negative connotation, conflict is synonymous with the terms violence, destruction and irrationality. 
This view is consistent with the dominant attitudes about group behavior in the 1930s and 1940s. Conflict is seen as a dysfunctional outcome resulting from poor communication, a lack of trust and openness among people, and a manager's failure to respond to employee needs and aspirations.

\section{The Human Relations View}

This view argues that conflict is a natural event in all groups and organizations. Conflict is something that cannot be avoided, therefore the existence of conflict must be accepted and rationalized in such a way that it is beneficial for improving organizational performance. This view dominated conflict theory from the late 1940s to the mid-1970s (Hall \& Hall, 2003)

\section{The Interactionist View}

Researched by Garrety \& Badham (2000) this view tends to encourage conflict, on the basis of an assumption that cooperative, calm, peaceful, and harmonious groups tend to be static, apathetic, non-aspirational, and not innovative. Therefore, according to this school of thought, conflict needs to be maintained at a minimum level on an ongoing basis, so that the group remains vibrant (viable), self-critical (self-critical), and creative. Stoner and Freeman (1989) divide the view of conflict into two parts, namely the traditional view (old view) and the modern view (current view).

\section{Factors Causing Conflict}

According to Robbins et. Al (1996), conflicts arise because there are conditions that underlie them (antecedent conditions). These conditions, which are also known as sources of conflict, consist of three categories, namely: (a) Communication, poor communication, in the sense of communication that creates misunderstanding between the parties involved, can be a source of conflict. A research result shows that semantic difficulties, insufficient information exchange, and disturbances in communication channels are barriers to communication and become antecedent conditions for conflict creation.(b) Structure, the term structure in this context is used in a sense that includes: size (group), degree of specialization given to group members, clarity of jurisdiction (work area), compatibility between members' goals and group goals, leadership style, reward system, and degree of dependence between groups. . Research shows that group size and degree of specialization are variables that drive conflict. The larger the group, and the more specialized activities, the greater the likelihood of conflict. (c) Personal Variables, other potential sources of conflict are personal factors, which include: the value system that each individual has, personality characteristics that cause the individual to be unique (idiosyncrasies) and different from other individuals. The fact shows that certain personality types, for example, individuals who are highly authoritarian, dogmatic, and have low regard for others, are a potential source of conflict. If one of these conditions occurs in a group, and employees are aware of it, then the perception arises that in the group there is a conflict. This situation is called perceived conflict. Then, if individuals are emotionally involved, and they feel anxious, tense, frustrated, or hostile, then the conflict turns into a felt conflict. Furthermore, the conflict that its existence has realized and felt will turn into a real conflict, if the parties involved manifest it in the form of behavior. For example, verbal attacks, threats to other parties, physical attacks, riots, strikes, and so on.

There are different types of conflict, depending on the basis on which the classification was made.

There are those who divide conflict based on the parties involved in it, there are those who divide conflict in terms of function and there are also those who divide conflict according to one's position in an organization. 


\section{Conflict Seen from a person's Position in the Organizational Structure}

This type of conflict is also called intra-organizational conflict. Judging from one's position in the organizational structure, Winardi divides conflict into four types. The four types of conflict are as follows: (1) Vertical conflicts, namely conflicts that occur between employees who have different positions in the organization. For example, between superiors and subordinates.(2) Horizontal conflict, namely conflict that occurs between those who have the same position or level in the organization. For example, conflicts between employees, or between departments at the same level. (3) Line-staff conflicts, namely conflicts that occur between line employees who normally hold command positions and staff officers who normally serve as advisors in the organization. (4) Role conflict, namely conflict that occurs because a person has more than one role that contradicts one another (Rahim, 2002).

\section{The Conflict Judging by the Parties involved in it}

Based on the parties involved in the conflict, Stoner divides the conflict into five types, namely: (1) Conflict within the individual (conflict within the individual), namely this conflict occurs when a person has to choose conflicting goals, or because of the demands of a task that exceeds his limits. Included in this individual conflict, according to Altman, are frustration, purpose conflict and role conflict. (2) Conflict between individuals, which occurs because of differences in personality between one individual and another. (3) Conflict between individuals and groups, which occurs when individuals fail to conform to the norms of the group in which they work. (4) Conflict between groups in the same organization (conflict among groups in the same organization), wherein this conflict occurs because each group has different goals and each tries to achieve it. This problem occurs because as groups become more attached to their own goals or norms, they become more competitive with each other and try to disrupt the activities of their competitors, and thus this affects the organization as a whole. (5) Conflict among organizations, namely conflict occurs when actions taken by the organization have a negative impact on other organizations. For example, in the struggle for the same resource (Della Porta, 2001)

\section{Conflict Judging from Function}

Judging from the function, Robbins divides conflict into two types, namely: (1) Functional conflicts are conflicts that support the achievement of group goals and improve group performance. (2) Dysfunctional conflict is a conflict that hinders the achievement of group goals. According to Robbins, the boundaries that determine whether a conflict is functional or dysfunctional are often unclear (blurred). A conflict may be functional for one group, but not functional for another. Likewise, conflicts can be functional at some times, but not functional at other times. The criterion that distinguishes whether a conflict is functional or dysfunctional is the impact of the conflict on group performance, not on individual performance. If the conflict can improve group performance, even though it is not satisfactory for individuals, then the conflict is said to be functional. Conversely, if the conflict only satisfies the individual, but reduces the performance of the group, then the conflict is dysfunctional (Zaugg, 2008).

\section{Strategy in Conflict Management}

\section{Avoid}

Avoiding conflict can be done when the issue or problem that triggered the conflict is not very important or if the potential for confrontation is out of balance with the consequences it will have (Kaushal \& Kwantes, 2006). . Avoidance is a strategy that allows the parties to the confrontation to calm down. The nurse manager involved in the conflict can push the issue 
aside by saying "Let both parties take the time to think about this and set a date for discussion".

\section{Accomodating}

Give others the opportunity to set problem-solving strategies, especially when the issue is important to others. This allows for collaboration by giving them the opportunity to make decisions. Nurses who are part of the conflict can accommodate the other party by putting the needs of the other party first.

\section{Competition}

Use this method if you believe you have more information and more skills than others or when you don't want to compromise your values. This method may cause conflict but may be an important method for security reasons.

\section{Compromise or Negotiation}

Each of them gives and offers something at the same time, gives and receives each other, and minimizes the shortcomings of all parties that can benefit all parties.

\section{Problem Solving or Collaboration}

According to Dossick \& Neff (2011) win-win solution where the individuals involved have the same work goal. There needs to be a commitment from all parties involved to support and care for one another.

\section{Problem Solving}

In the problem solving strategy, the basic assumption is that all parties have a desire to handle the conflict that occurs and therefore it is necessary to find measures that can satisfy the parties to the conflict. On the basis of these assumptions, the problem solving strategy must always go through two important stages, namely the process of finding ideas and the process of maturing them. The results of research that has been conducted by the United States prove that problem solving efforts become more productive when all ideas are collected before they are discussed.

The same research also proves that the quality of the solution will be better if the leader first discusses the problem before discussing the solution. Since the purpose of solving a problem is to discuss various kinds of possibilities, it cr creates the possibility of differing opinions, not eliminating them.

\section{Conclusion}

Conflict between oneself and someone can occur because of differences in roles (superiors and subordinates), personalities, and needs (vertical conflict). Self-conflict with the group can occur because the individual is under pressure from the group, or the individual has violated group norms so that the group is hostile or ostracized by the group. Changed vision, mission, goals, objectives, policies, strategies and organizational actions. Groups with groups within an organization can occur because of the ambition of one or both groups to be more powerful, there are groups that oppress, there are groups that violate the cultural norms of other groups, other group injustice, and the greed of other groups (primordial conflict).

\section{References}

Balasubramanian, S., \& Bhardwaj, P. (2004). When not all conflict is bad: Manufacturingmarketing conflict and strategic incentive design. Management Science, 50(4), 489502. 
Della Porta, D. (2001). A judges' revolution? Political corruption and the judiciary in Italy. European Journal of Political Research, 39(1), 1-21.

Dossick, C. S., \& Neff, G. (2011). Messy talk and clean technology: communication, problem-solving and collaboration using Building Information Modelling. The Engineering Project Organization Journal, 1(2), 83-93.

Garrety, K., \& Badham, R. (2000). The politics of socio-technical intervention: An interactionist view. Technology Analysis \& Strategic Management, 12(1), 103-118.

Hall, C., \& Hall, E. (2003). Human relations in education. Routledge.

Kaushal, R., \& Kwantes, C. T. (2006). The role of culture and personality in choice of conflict management strategy. International journal of intercultural relations, 30(5), 579-603.

Nemeth, C. J., Personnaz, B., Personnaz, M., \& Goncalo, J. A. (2004). The liberating role of conflict in group creativity: A study in two countries. European journal of social psychology, 34(4), 365-374.

Rahim, M. A. (2002). Toward a theory of managing organizational conflict. International journal of conflict management, 13(3).

Robbins, M. S., Alexander, J. F., Newell, R. M., \& Turner, C. W. (1996). The immediate effect of reframing on client attitude in family therapy. Journal of Family Psychology, 10(1), 28.

Zaugg, R. (2008). Judging foreigners. Conflict strategies, consular interventions and institutional changes in eighteenth-century Naples. Journal of modern Italian studies, 13(2), 171-195. 